DOI: 10.1002/adfm.((please insert DOI)

\title{
Templated Assembly of pH-Labile Polymer-Drug Particles for Intracellular Drug Delivery
}

By Jiwei Cui, Yan Yan, Yajun Wang, and Frank Caruso*

[*] Prof. F. Caruso, Dr. J. Cui, Dr. Y. Yan, Dr. Y. Wang

Department of Chemical and Biomolecular Engineering

The University of Melbourne

Parkville, Victoria 3010 (Australia)

E-mail: fcaruso@unimelb.edu.au

Keywords: Nanomedicine, Drug delivery, Mesoporous silica, Polymer-drug conjugates, Nanotechnology

We report the preparation of $\mathrm{pH}$-labile polymer-drug particles via mesoporous silicatemplated assembly for anticancer drug delivery into cancer cells. The polymer-drug conjugate was synthesized via thiol-maleimide click chemistry using thiolated poly(methacrylic acid) (PMA $\mathrm{PH}_{\mathrm{SH}}$ ) and a pH-labile doxorubicin (Dox) derivative. Drug-loaded polymer particles that are stable under physiological conditions were obtained through infiltration of the conjugates into mesoporous silica particles, followed by cross-linking of the PMA $_{S H}$ chains, and subsequent removal of the porous silica templates. The encapsulated Dox was released from the particles through cleavage of the hydrazone bonds between Dox and $\mathrm{PMA}_{\mathrm{SH}}$ at endosomal/lysosomal $\mathrm{pH}$. Cell viability assays showed that the assembled $\mathrm{PMA} \mathrm{SH}_{\mathrm{S}}$ particles have negligible toxicity to LIM1899 human colorectal cancer cells. In comparison, Dox-loaded $\mathrm{PMA}_{\mathrm{SH}}$ particles caused significant cell death following internalization. The reported particles represent a novel and versatile class of stimuli-responsive carriers for controlled drug delivery. 


\section{Introduction}

Submitted to

The convergence of nanotechnology and medicine for the treatment of diseases is a rapidly growing research field. ${ }^{[1,2]}$ In recent years, polymer carriers with finely controlled and responsive properties have received increasing interest for biomedical applications. ${ }^{[3-5]}$ These carries include polymer micelles, polymersomes, dendrimers, polymer brushes, polymer capsules and polymer particles. ${ }^{[6-8]}$ Recently, we reported a facile and robust approach to prepare polymer replica particles via templating mesoporous silica (MS) particles. ${ }^{[9]}$ Briefly, polymers were infiltrated into MS particles, followed by cross-linking and subsequent removal of the template, resulting in polymer replica particles. A suite of replica particles were prepared from different polymers, including polyelectrolytes, ${ }^{[10]}$ polypeptides, ${ }^{[11]}$ proteins, ${ }^{[12]}$ polysaccharides, ${ }^{[13]}$ or hydrophobic polyesters ${ }^{[14]}$ by templating MS particles. The general applicability of this technique not only affords particles of diverse chemical composition but also facilitates the design of key physicochemical properties, including size, nanostructure and functionality, which are important for tailor-made drug delivery systems. ${ }^{[9]}$

To achieve controlled drug release, polymer-based carrier vehicles require triggered release mechanisms. ${ }^{[15,16]}$ Such mechanisms can be used to prevent drug leakage and deactivation during circulation and allow triggered release of the therapeutics at targeted sites in the presence of specific physiological stimuli. ${ }^{[17]} \mathrm{pH}$-triggered release is one of the mostly used mechanisms to effect release of the active drugs after endocytosis, ${ }^{[20]}$ as polymer carriers are subject to acidification when internalized from the slightly alkaline extracellular conditions into acidic environments ( $\mathrm{pH}$ 5-6) inside endosomal/lysosomal compartments. ${ }^{[21]}$ Consequently, $\mathrm{pH}$-responsive mechanisms have been engineered in a range of drug carriers, such as self-assembled polymer micelles ${ }^{[22,23]}$ and polymer particles, ${ }^{[24,25]}$ for triggered release. Although in our previous work enzymatic and reductive mechanisms were exploited 
in polymer replica systems for triggered drug release, ${ }^{[18,19]}$ a delivery system that exploits the

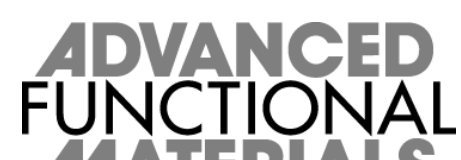
advantages of polymer replica particles and a $\mathrm{pH}$-labile mechanism is yet to be reported.

In this study, we combine $\mathrm{pH}$-labile polymer-drug conjugates and MS templating to prepare $\mathrm{pH}$-responsive particles for intracellular drug delivery. Submicrometer-sized MS particles with larger mesopores $(15-30 \mathrm{~nm})$ were used as templates and thiolated poly(methacrylic acid) (PMA $\mathrm{PMH}_{\mathrm{SH}}$ ) was chosen as the host polymer for polymer-drug conjugate synthesis. The anticancer drug (i.e., doxorubicin) was functionalized with a pH-labile linker and conjugated to $\mathrm{PMA}_{\mathrm{SH}}$ polymers. The resultant polymer-drug conjugates were then infiltrated into MS particles, followed by cross-linking and subsequent removal of the template, resulting in polymer-drug particles (Scheme 1). This approach offers a number of distinct advantages. Firstly, drug-loaded polymer particles with $\mathrm{pH}$-dependent release properties are obtained by a single-step macromolecular assembly step. Secondly, this facile method is versatile and applicable to systems with different polymer-drug conjugates. Thirdly, submicrometer-sized mesoporous silica particles with large mesopores (15-30 nm) are used for the preparation of polymer particles, which offers a new approach to assemble polymer particles with large molecular weight macromolecules for biological applications. The resultant drug-loaded particles showed significant cytotoxicity to cultured colorectal cancer cells. To our knowledge, this is the first report where MS particles have been used to prepare pH-labile polymer-drug particles for drug delivery.

\section{Results and Discussion}

\subsection{Templated Assembly of Polymer-Drug Particles}


For the preparation of polymer-drug particles, we designed a $\mathrm{pH}$-cleavable polymer-drug conjugate as the building block. Firstly, PMA $\mathrm{SH}_{\mathrm{H}}$ was synthesized via $\mathrm{N}$-(3dimethylaminopropyl)- $N$ '-ethylcarbodiimide hydrochloride (EDC)-mediated amide bond formation between the carboxyl groups of PMA and amine groups of pyridine dithioethylamine (PDA), followed by removal of the pyridine-2-thione groups. ${ }^{[26]}$ Thiol modification was used to effect both drug conjugation and particle assembly in the MS templates. The degree of thiol functionalization was characterized by measuring the absorbance of the released pyridine-2-thione $\left(\lambda_{\max }=343 \mathrm{~nm}\right)$, and then quantified from a calibration curve of PDA, which corresponded to 13.5 mol\% modification. A “clickable” and pH-sensitive doxorubicin (Dox) derivative (MAL-Dox) was synthesized by introducing maleimide and hydrazone groups into the compound while maintaining the quinine ring intact for drug activity (Scheme 2a). ${ }^{[27]}$ Next, MAL-Dox was conjugated onto PMA ${ }_{S H}$ via thiolmaleimide click chemistry to form polymer-drug conjugates ( $\mathrm{PMA}_{\mathrm{SH}^{-}}$-Dox). The degree of Dox functionalization was characterized by using the absorbance $\left(\lambda_{\max }=480 \mathrm{~nm}\right)$ of $\mathrm{PMA}_{\mathrm{SH}^{-}}$ Dox and a Dox standard curve, corresponding to 4 mol \% modification, leaving 9.5 mol\% of free thiol groups on the polymer backbone for further cross-linking to form polymer particles (Scheme 2b).

To prepare polymer-drug particles, submicrometer-sized MS particles with large mesopores were used as templates, which were synthesized according to a modified literature method. ${ }^{[28]}$ Transmission electron microscopy (TEM) and scanning electron microscopy (SEM) reveal that the size of the resultant MS particles is 700-900 nm (Figure 1a,b). The particles have a surface area of $893 \mathrm{~m}^{2} \mathrm{~g}^{-1}$, smaller mesopores in the 2-3 $\mathrm{nm}$ range and larger mesopores between $15-30 \mathrm{~nm}$, as measured by nitrogen sorption experiments. Interstitial pores are clearly observed from both TEM and SEM images (Figure 1). 


\section{Submitted to

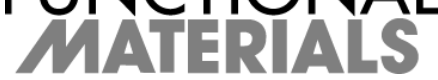

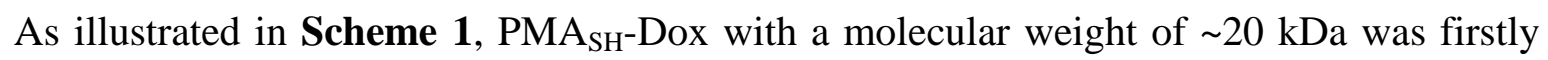
infiltrated into the nanopores of the amine-modified MS particles. Here, MS particles were incubated in a $\mathrm{PMA}_{\mathrm{SH}}$-Dox solution for $1 \mathrm{~h}$, resulting in a red pellet after isolation of the particles. To obtain polymer particles that are stable at physiological conditions (pH 7.2), covalent cross-linking of the polymer chains was required. ${ }^{[9]}$ In our approach, chloramine T was used to convert the free thiol groups on $\mathrm{PMA}_{\mathrm{SH}^{-}}$-Dox into bridging disulfide linkages. After removal of the MS templates, $\mathrm{PMA}_{\mathrm{SH}_{\mathrm{H}}}$-Dox particles were obtained. TEM images showed that the resultant PMA $\mathrm{SH}_{\mathrm{SH}}$-Dox particles remained intact with a diameter of $\sim 500 \mathrm{~nm}$ (Figure 1c), representing about 30\% shrinkage from the original template size. This particle size is consistent with the results from dynamic light scattering measurements (Figure 1d). Confocal laser scanning microscopy (CLSM) revealed that the $\mathrm{PMA}_{\mathrm{SH}}$-Dox particles were well dispersed in aqueous solution (Figure 1e,f). The red fluorescence arising from the immobilized Dox confirmed that $\mathrm{PMA}_{\mathrm{SH}}-\mathrm{Dox}$ was loaded in the particles. To determine the amount of Dox loaded, we examined the particles by flow cytometry and UV-vis spectrophotometry. The number of $\mathrm{PMA}_{\mathrm{SH}^{-}}$-Dox particles was determined by flow cytometry. The PMA $\mathrm{SH}_{\mathrm{S}}$-Dox particles were then exposed to a dithiothreitol (DTT) solution (pH 8) and kept at $\mathrm{pH} 4$ overnight. Using a UV-vis absorbance calibration curve, we deduced that the drug loading in each particle was approximately $5.4 \times 10^{-15} \mathrm{~g}$.

\subsection{Intracellular Drug Delivery}

As an initial test to verify the utility of the obtained $\mathrm{PMA}_{\mathrm{SH}_{\mathrm{H}}}$-Dox particles for drug release, we monitored the drug release at $\mathrm{pH} 7.2$ and 5.5 using fluorescence spectrophotometry. Drug release under physiological conditions ( $\mathrm{pH}$ 7.2) was significantly lower than that under acidic conditions ( $\mathrm{pH}$ 5.5) (Figure 2). There was approximately 80\% release at $\mathrm{pH} 5.5$ within the 
Submitted to 1 ATERIAS

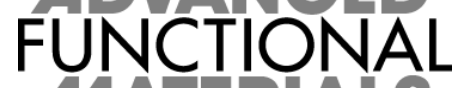

first $24 \mathrm{~h}$, indicating that Dox release from the particles was largely $\mathrm{pH}$-dependent due to the pH-labile linker between the polymer and drug.

The toxicity of $\mathrm{PMA}_{\mathrm{SH}}$-Dox particles in LIM1899 human colorectal cancer cells was investigated using the 3-(4,5-dimethylthiazol-2-yl)-2,5-diphenyltetrazolium bromide (MTT) cell viability assay (Figure 3). For the MTT assay, the drug-loaded particles were incubated with adherent LIM1899 cells at various particle to cell ratios (from 1:1 to 1000:1) for $43 \mathrm{~h}$. As a control, LIM1899 cancer cells were also treated with an equal number of non-drug loaded PMA $\mathrm{SH}_{\mathrm{SH}}$ particles (T2, T3, T4, and T5). The results indicated that the PMA $\mathrm{AH}_{\mathrm{SH}}$ particles have a negligible effect on cell viability, even at high particle to cell ratios (1000:1). This is consistent with cell viability results obtained using PMA $\mathrm{PH}_{\mathrm{SH}}$ capsules. ${ }^{[29]}$ However, as shown in Figure 3, a significant decrease in the cell viability with increasing number of $\mathrm{PMA}_{\mathrm{SH}}$-Dox particles was observed, exhibiting dose-responsive behavior (T6, T7, T8, and T9). The IC50 value of PMA $\mathrm{SH}_{\mathrm{SH}}$-Dox particles is $\sim 28.5 \mathrm{nM}$, which is lower than the IC50 value of free Dox $(62.1 \mathrm{nM}) .{ }^{[30]}$ This indicates that $\mathrm{PMA}_{\mathrm{SH}}$-Dox particles enhanced drug efficacy.

The major mechanism of Dox toxicity to cells is believed to be the inhibition of the action of topoisomerase II or intercalation of DNA strands, leading to DNA double-strand breaks and inhibition of DNA replication and transcription. ${ }^{[31]}$ This means that nucleus location of Dox results in maximal drug efficacy. Consequently, we evaluated the intracellular distribution of Dox using deconvolution fluorescence microscopy. Figure 4 shows the representative images of LIM1899 cells treated with $\mathrm{PMA}_{\mathrm{SH}_{\mathrm{H}}}$-Dox particles at a particle to cell ratio of 1000:1. After incubation for $24 \mathrm{~h}$, accumulation of red fluorescence in the cell nuclei was apparent, with nearly all of the nuclei containing Dox (Figure 4a). Dox-associated fluorescence was also present in the cytoplasm, and largely concentrated in vesicles at the perinuclear region (see the circles and arrows in Figure 4c and 4d). This suggests that Dox was released from the $\mathrm{PMA}_{\mathrm{SH}^{-}}$-Dox particles in the acidic intracellular environment of 
Submitted to

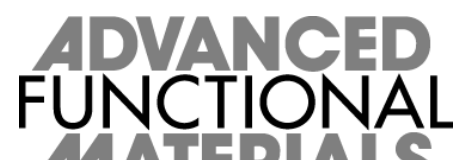

endosomal/lysosomal compartments, ${ }^{[32]}$ and that the released Dox was further translocated to the nuclei. It is worth noting that the internalized $\mathrm{PMA}_{\mathrm{SH}}$-Dox particles may also be degraded in the process of endocytosis, as studies have suggested that a number of disulfide reduction sites are present within a cell, such as the exofacial thiols on the cell membrane ${ }^{[33]}$ and redox enzymes in endosomes/lysosomes. ${ }^{[34]}$ The negligible toxicity of the carrier system and the $\mathrm{pH}$-dependent release of drug from polymer particles make this polymer-drug carrier interesting for drug delivery applications.

\section{Conclusions}

In summary, we have presented a facile method for the assembly of drug-loaded polymer particles using $\mathrm{pH}$-cleavable polymer-drug $\left(\mathrm{PMA}_{\mathrm{SH}_{\mathrm{H}}}\right.$-Dox) conjugates. Submicron-sized particles were obtained by preloading polymer-drug conjugates into MS particles, followed by cross-linking and subsequent removal of the templates. The drug-loaded particles were stable at physiological conditions and allowed the triggered release of the encapsulated Dox at low $\mathrm{pH}$ via cleavage of the hydrazone bonds between the polymer and Dox. Cell viability assays showed that Dox was effectively released from the $\mathrm{PMA}_{\mathrm{SH}}$-Dox particles after internalization by LIM1899 human colorectal cancer cells, resulting in significant cell death. These particles could potentially be used for the controlled release of drugs in acidic subcellular organelles.

\section{Experimental}

Materials: Tetraethyl orthosilicate (TEOS), (3-aminopropyl)triethoxysilane (APTES), cetyltrimethylammonium bromide (CTAB), poly(acrylic acid) (PAA, $M_{\mathrm{w}} \sim 250 \mathrm{kDa}, 35 \mathrm{wt} \%$ solution in water), $N$-(3-dimethylaminopropyl)- $N$ '-ethylcarbodiimide hydrochloride (EDC), 
Submitted to

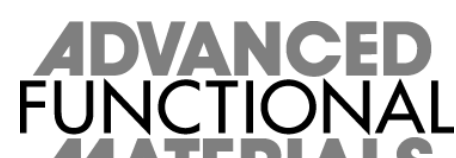

$N$-Chloro-p-toluenesulfonamide sodium salt (Chloramine T), dithiothreitol (DTT), 2-(Nmorpholino)ethanesulfonic acid hydrate (MES), 3-( $N$-morpholino)propanesulfonic acid (MOPS), trifluoroacetic acid (TFA), and ammonia (28-30\%) were obtained from SigmaAldrich (Australia). Poly(methacrylic acid, sodium salt) (PMA, $M_{\mathrm{w}} 15 \mathrm{kDa}$, $30 \mathrm{wt} \%$ solution in water) was from Polysciences, Inc. (USA). Pyridine dithioethylamine (PDA) was purchased from Shanghai SpeedChemical Co. Ltd. (China). $N$-( $\varepsilon$-Maleimidocaproic acid) hydrazide (EMCH) was obtained from Pierce Biotechnology, Inc. (Australia). Doxorubicin hydrochloride (Dox, purity 99\%) was from OChem Inc. (USA). Roswell Park Memorial Institute (RPMI) 1640 medium, fetal bovine serum (FBS), Dulbecco’s Phosphate-Buffered Saline (DPBS) and 3-(4,5-dimethylthiazol-2-yl)-2,5-diphenyltetrazolium bromide (MTT) were purchased from Invitrogen (Australia). The chemicals above were used without further purification. All other chemicals were analytical reagents unless otherwise stated. The water used in all experiments was prepared in a three-stage Millipore Milli-Q Plus 185 purification system and had a resistivity greater than $18.2 \mathrm{M} \Omega \cdot \mathrm{cm}$.

Synthesis of $P M A_{P D A}$ : PMAPDA was synthesized via EDC-mediated amide bond formation between the carboxyl groups of PMA and amine groups of PDA [26]. In a typical experiment, a PMA solution (360 mg of $30 \mathrm{wt} \%$ solution, 1 equiv. of MA) was diluted into $5 \mathrm{~mL}$ of phosphate buffer (0.1 M, pH 7.2). The resulting solution was incubated with EDC (76.7 mg, 0.4 equiv.) with stirring for $15 \mathrm{~min}$. Subsequently, PDA (44.5 mg, 0.2 equiv.) in phosphate buffer was added to the mixture and the $\mathrm{pH}$ was adjusted to 7.2. The reaction was allowed to proceed overnight. The resulting mixture was placed inside a dialysis membrane (molecular weight cut-off 7,000, Thermo) and dialyzed extensively against water, filtered with a $0.2 \mu \mathrm{m}$ syringe filter, and isolated via lyophilization.

Synthesis of Maleimide-Modified Doxorubicin (MAL-Dox): Dox was modified with EMCH via hydrazone click chemistry to introduce maleimide groups at the 13-keto position, as 
Submitted to FUNCTIONAL described in literature (Scheme 2a) [35-37]. Firstly, $24 \mathrm{mg}$ of Dox (4.14 $\times 10^{-5} \mathrm{~mol}, 1$ equiv.) and $28 \mathrm{mg}$ of EMCH trifluoroacetate salt $\left(1.242 \times 10^{-4} \mathrm{~mol}, 3\right.$ equiv.) were dissolved in 12 $\mathrm{mL}$ of dry methanol in a $50 \mathrm{~mL}$ round-bottom flask. Then, $40 \mu \mathrm{L}$ of TFA was added to catalyze the reaction, which was protected from light and stirred overnight. The resultant solution was concentrated to $1 \mathrm{~mL}$ by rotary evaporation and precipitated in dry ethyl acetate three times. The product was collected by centrifugation and dried in vacuum. The dry methanol and ethyl acetate were prepared by drying with a molecular sieve, followed by distillation.

Synthesis of Polymer-Drug Conjugates (PMA $A_{S H^{-}}$Dox): To expose thiol groups, $20 \mathrm{mg}$ of $\mathrm{PMA}_{\mathrm{PDA}}$ was dissolved at a concentration of $50 \mathrm{mg} \mathrm{mL}^{-1}$ with $0.25 \mathrm{M}$ of DTT solution in MOPS buffer (10 mM, pH 8) for $20 \mathrm{~min}$ at $37^{\circ} \mathrm{C}$, which resulted in thiol-functionalized PMA (PMA $\left.{ }_{S H}\right)$. The mixture was diluted with MES buffer (50 mM, pH 6.5) and purified with a NAP-25 Sephadex column, which was pre-equilibrated with MES buffer. The resultant $\mathrm{PMA}_{\mathrm{SH}}$ in MES buffer was mixed with $6 \mathrm{mg}$ of MAL-Dox under stirring and then incubated for $2 \mathrm{~h}$. The product was purified with a Sephadex column and lyophilized to obtain a red powder of PMA $\mathrm{SH}_{-}$-Dox (Scheme 2b).

Synthesis of Mesoporous Silica Particles: MS particles were synthesized according to a modified literature method [28]. Briefly, $1.1 \mathrm{~g}$ of CTAB was completely dissolved in $50 \mathrm{~mL}$ of water with stirring. Subsequently, $4.28 \mathrm{~g}$ of PAA solution (250 kDa, $35 \mathrm{wt} \%$ solution) was added with vigorous stirring at room temperature $\left(25^{\circ} \mathrm{C}\right)$ until a clear solution was obtained. Next, $3.5 \mathrm{~mL}$ of ammonia (28-30\%) was added to the above solution with vigorous stirring, resulting in a milky suspension. After further stirring for $20 \mathrm{~min}, 4.46 \mathrm{~mL}$ of TEOS was added to the above solution. The mixture was stirred for $48 \mathrm{~h}$ at room temperature $\left(25^{\circ} \mathrm{C}\right)$. The as-synthesized particles were washed with Milli-Q water twice and ethanol three times, and finally dispersed in ethanol. 
Submitted to 1 ATERIAS

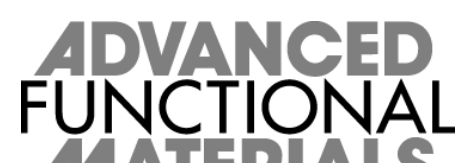

The PAA and surfactants were removed by extraction with ethanol/HCl solution. Typically, $900 \mathrm{mg}$ of MS particles was dispersed in a mixture of $100 \mathrm{~mL}$ of ethanol and $10 \mathrm{~mL}$ of $\mathrm{HCl}$ (37\%), which was kept refluxing $\left(80^{\circ} \mathrm{C}\right)$ for $16 \mathrm{~h}$. The particles were then washed with water and ethanol three times. The extraction step was repeated three times.

The MS templates were then functionalized with a layer of primary amine groups by APTES modification. In this process, the MS particles were dispersed in ethanol with a concentration of $20 \mathrm{mg} \mathrm{mL}^{-1}$ by sonication (Bransonic 1510E-DTH ultrasonic cleaner) for 20 min before ammonia and APTES were added to the suspension. The volume ratio of ethanol:ammonia:APTES was fixed at 20:1:1, and the suspension was allowed to stir overnight.

Templated Assembly of $P M A_{S H}-$ Dox Particles: Approximately 3 mg of MS particles were dispersed in $5 \mathrm{mg} \mathrm{mL}^{-1}$ of $\mathrm{PMA}_{\mathrm{SH}^{-}}$-Dox solution at $\mathrm{pH} 6.5$ (MES buffer, $50 \mathrm{mM}$ ) under constant shaking for $1 \mathrm{~h}$. Subsequently, the particles were isolated by centrifugation and washed twice with MES buffer. The pellet was dispersed in $50 \mu \mathrm{L}$ of MES buffer and exposed to a $10 \mathrm{mM}$ solution of Chloramine T in MES buffer ( $\mathrm{pH} \mathrm{6.5,} 50 \mathrm{mM}$ ) for $2 \mathrm{~min}$. After two washing cycles with PBS buffer, the MS templates were dissolved with a $0.5 \mathrm{M}$ $\mathrm{HF} / 8 \mathrm{M} \mathrm{NH}_{4} \mathrm{~F}$ solution (pH 7 ). Caution! HF is highly toxic. Extreme care should be taken when handling HF solution and only small quantities should be prepared. Details of this process are given in Scheme 1. The resultant $\mathrm{PMA}_{\mathrm{SH}^{-}}$-Dox particles were centrifuged and washed three times with PBS buffer.

Dox Release from $\mathrm{PMA}_{S H^{-}}$Dox Particles: Drug release experiments were performed at $\mathrm{pH}$ values of 7.2 and $5.5\left(37^{\circ} \mathrm{C}\right)$ respectively $\left(\lambda_{\mathrm{ex}}=470 \mathrm{~nm} ; \lambda_{\mathrm{em}}=560 \mathrm{~nm}\right)$. Time-dependent release of Dox from the particles was studied for $48 \mathrm{~h}$. The supernatant was obtained by centrifuging the samples and the fluorescence intensity was measured at $\mathrm{pH} 5.5$ with a fluorometer at various time points. 
Submitted to

Cell Viability Assay: LIM1899 cells were cultured in RPMI 1640 media containing 10\% FBS and ADDS (10.8 $\mathrm{g} \mathrm{mL}^{-1}$ thioglycerol, $0.025 \mathrm{U} \mathrm{mL}^{-1}$ insulin, $1 \mathrm{~g} \mathrm{~mL}^{-1}$ hydrocortisone) at $37{ }^{\circ} \mathrm{C}$ in a humidified atmosphere containing $5 \% \mathrm{CO}_{2}$. Cell viability was measured by reduction of MTT, as described previously [38]. Briefly, LIM1899 cells were seeded at $1 \times$ $10^{4}$ cells per well in 96-well plates and incubated with particles at various particle-to-cell ratios in $200 \mu \mathrm{L}$ growth media for $43 \mathrm{~h}$. After treatment, cells were further incubated with fresh medium containing MTT $\left(0.5 \mathrm{mg} \mathrm{mL}^{-1}\right)$ for $4 \mathrm{~h}$. The resulting blue formazan was solubilized using $150 \mu \mathrm{L}$ of acidified isopropanol $(0.04 \mathrm{~N} \mathrm{HCl})$ and the absorbance at $570 \mathrm{~nm}$ was measured with a plate reader (Multiskan Ascent, Thermo Scientific). The cell viability of treated cells was normalized as a percentage of untreated cells. Data are shown as the mean \pm the standard error from three independent experiments performed in triplicate.

Intracellular Drug Release: LIM1899 cells were plated at $8 \times 10^{4}$ cells/well into 8-well Lab-Tek I chambered coverglass slides (Thermo Fisher Scientific, Rochester) and allowed to adhere overnight. Cells were then incubated with $\mathrm{PMA}_{\mathrm{SH}}$-Dox particles at a particle-to-cell ratio of 1000:1 for $43 \mathrm{~h}\left(37^{\circ} \mathrm{C}, 5 \% \mathrm{CO}_{2}\right)$, followed by three washes with DPBS. Cells were fixed with $4 \%$ paraformaldehyde for $20 \mathrm{~min}$ at $25^{\circ} \mathrm{C}$, and incubated with Hoechst 33342 (2 $\mu \mathrm{g} \mathrm{mL}{ }^{-1}$ ) for $20 \mathrm{~min}$ at $25^{\circ} \mathrm{C}$ to counterstain the nucleus.

Characterization Methods: Transmission electron microscopy (TEM, Philips CM120 BioTWIN, operated at $120 \mathrm{kV}$ ) and scanning electron microscopy (SEM, Philips XL30, operated at $10 \mathrm{kV}$ ) were used to examine the particle morphologies. The TEM samples (1 $\mu \mathrm{L}$ ) were placed onto Formvar-coated copper grids and allowed to air-dry. The SEM samples (2 $\mu \mathrm{L}$ ) were placed onto silicon wafers and allowed to air-dry prior to gold sputter-coating. Size distributions of the $\mathrm{PMA}_{\mathrm{SH}}$-Dox particles were measured with a Malvern High Performance Particle Sizer (HPPS). Each measurement was run 10 times. The surface areas and porosities of the MS particles were measured by a Micromeritics Tristar surface area and 
Submitted to

porosity analyzer at $77 \mathrm{~K}$, using nitrogen as the adsorption gas. The surface area was calculated using the Brunauer-Emmett-Teller (BET) method, and the pore diameter distributions were derived from the desorption branch by the Barrett-Joyner-Halenda (BJH) method. Confocal microscopy images were obtained using a Leica TCS-SP2 confocal laser scanning microscope (CLSM). Deconvolution fluorescence microscopy was performed on a DeltaVision (Applied Precision, USA) microscope with a $60 \times 1.42$ NA oil objective with a standard FITC/TRITC/CY5 filter set. Images were processed with Imaris (Bitplane) using the maximum intensity projection. The drug amount loaded in the polymer particles was determined using an Agilent 8453 diode-array UV-vis spectrophotometer (Agilent Technologies, CA). The degree of PDA functionalization was quantified via absorbance readings at $343 \mathrm{~nm}$ using a NanoDrop 1000 spectrophotometer (Thermo Scientific, Australia). Polymer particle counting was performed using CyFlow Space (Partec GmbH) flow cytometer. pH-dependent drug release was monitored using a Horiba Fluorolog-3 Model FL3-22 spectrofluorometer (Jobin Yvon Inc., USA) equipped with a HgXe lamp (increment size, $1 \mathrm{~nm}$; excitation and emission slit widths, $5 \mathrm{~nm}$ ). The $\mathrm{pH}$ of solutions was measured with a Mettler-Toledo MP220 pH meter.

\section{Acknowledgements}

This work was supported by the Australian Research Council under the Federation Fellowship and Discovery Project schemes (F.C.), and National Health and Medical Research Council (NHMRC) Program Grant 487922 (F.C.). J.C is the recipient of an Australian Research Council Super Science Fellowship (FS110200025). We thank K. Liang for CLSM images and R. Chandrawati for assistance regarding the thiol-disulfide chemistry. G. K. Such is also thanked for helpful discussions. 
Submitted to

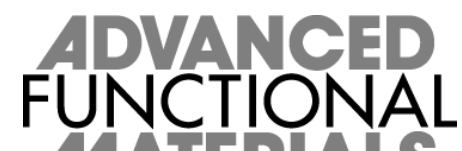

Received: ((will be filled in by the editorial staff))

Revised: ((will be filled in by the editorial staff))

Published online: ((will be filled in by the editorial staff))

[1] K. Riehemann, S. W. Schneider, T. A. Luger, B. Godin, M. Ferrari, H. Fuchs, Angew. Chem. Int. Ed. 2009, 48, 872.

[2] O. C. Farokhzad, R. Langer, ACS Nano 2009, 3, 16.

[3] R. Duncan, Curr. Opin. Biotechnol. 2011, 22, 492.

[4] Y. Wang, L. Hosta-Rigau, H. Lomas, F. Caruso, Phys. Chem. Chem. Phys. 2011, 13, 4782.

[5] J. H. Park, S. Lee, J. H. Kim, K. Park, K. Kim, I. C. Kwon, Prog. Polym. Sci. 2008, 33, 113.

[6] A. P. R. Johnston, G. K. Such, S. L. Ng, F. Caruso, Curr. Opin. Colloid Interface Sci. 2011, 16, 171.

[7] M. Elsabahy, K. L. Wooley, Chem. Soc. Rev. 2012, 41, 2545.

[8] N. Kamaly, Z. Xiao, P. M. Valencia, A. F. Radovic-Moreno, O. C. Farokhzad, Chem. Soc. Rev. 2012, 41, 2971.

[9] Y. Wang, A. D. Price, F. Caruso, J. Mater. Chem. 2009, 19, 6451.

[10] Y. Wang, A. Yu, F. Caruso, Angew. Chem. Int. Ed. 2005, 44, 2888.

[11] X. Zhang, M. Oulad-Abdelghani, A. N. Zelikin, Y. Wang, Y. Haîkel, D. Mainard, J.-C. Voegel, F. Caruso, N. Benkirane-Jessel, Biomaterials 2010, 31, 1699.

[12] Y. Wang, F. Caruso, Adv. Mater. 2006, 18, 795.

[13] D. Mertz, P. Tan, Y. Wang, T. K. Goh, A. Blencowe, F. Caruso, Adv. Mater. 2011, 5668.

[14] J. Cui, Y. Wang, J. Hao, F. Caruso, Chem. Mater. 2009, 21, 4310.

[15] M. A. C. Stuart, W. T. S. Huck, J. Genzer, M. Müller, C. Ober, M. Stamm, G. B. Sukhorukov, I. Szleifer, V. V. Tsukruk, M. Urban, Nat. Mater. 2010, 9, 101.

[16] A. P. R. Johnston, G. K. Such, F. Caruso, Angew. Chem. Int. Ed. 2010, 49, 2664.

[17] M. E. Fox, F. C. Szoka, J. M. J. Fréchet, Acc. Chem. Res. 2009, 42, 1141.

[18] Y. Wang, V. Bansal, A. N. Zelikin, F. Caruso, Nano Lett. 2008, 8, 1741.

[19] H. P. Yap, A. P. R. Johnston, G. K. Such, Y. Yan, F. Caruso, Adv. Mater. 2009, 21, 4348.

[20] K. Ulbrich, V. Šubr, Adv. Drug Delivery Rev. 2004, 56, 1023.

[21] J. R. Casey, S. Grinstein, J. Orlowski, Nat. Rev. Mol. Cell Biol. 2010, 11, 50.

[22] Y. Lee, S. Y. Park, H. Mok, T. G. Park, Bioconjugate Chem. 2008, 19, 525.

[23] M. Prabaharan, J. J. Grailer, S. Pilla, D. A. Steeber, S. Gong, Biomaterials 2009, 30, 5757.

[24] M. Shi, K. Ho, A. Keating, M. S. Shoichet, Adv. Funct. Mater. 2009, 19, 1689.

[25] J. K. Pokorski, K. Breitenkamp, L. O. Liepold, S. Qazi, M. G. Finn, J. Am. Chem. Soc. 2011, 133, 9242.

[26] O. Kulygin, A. D. Price, S.-F. Chong, B. Staedler, A. N. Zelikin, F. Caruso, Small 2010, 6, 1558.

[27] G. Minotti, P. Menna, E. Salvatorelli, G. Cairo, L. Gianni, Pharmacol. Rev. 2004, 56, 185.

[28] J.-G. Wang, H.-J. Zhou, P.-C. Sun, D.-T. Ding, T.-H. Chen, Chem. Mater. 2010, 22, 3829.

[29] Y. Wang, Y. Yan, J. Cui, L. Hosta-Rigau, J. K. Heath, E. C. Nice, F. Caruso, Adv. Mater. 2010, 22, 4293. 
Submitted to

\section{ADNANCED
FUNCIONALL \\ MATERALS}

[30] Y. Yan, C. J. Ochs, G. K. Such, J. K. Heath, E. C. Nice, F. Caruso, Adv. Mater. 2010, 22, 5398.

[31] A. Bodley, L. F. Liu, M. Israel, R. Seshadri, Y. Koseki, F. C. Giuliani, S. Kirschenbaum, R. Silber, M. Potmesil, Cancer Res. 1989, 49, 5969.

[32] C.-J. Ke, T.-Y. Su, H.-L. Chen, H.-L. Liu, W.-L. Chiang, P.-C. Chu, Y. Xia, H.-W. Sung, Angew. Chem. Int. Ed. 2011, 50, 8086.

[33] Y. Yan, Y. Wang, J. K. Heath, E. C. Nice, F. Caruso, Adv. Mater. 2011, 23, 3916.

[34] G. Saito, J. A. Swanson, K.-D. Lee, Adv. Drug Delivery Rev. 2003, 55, 199.

[35] D. Willner, P. A. Trail, S. J. Hofstead, H. D. King, S. J. Lasch, G. R. Braslawsky, R. S. Greenfield, T. Kaneko, R. A. Firestone, Bioconjugate Chem. 1993, 4, 521.

[36] D. Y. Furgeson, M. R. Dreher, A. Chilkoti, J. Controlled Release 2006, 110, 362.

[37] Z. Jia, L. Wong, T. P. Davis, V. Bulmus, Biomacromolecules 2008, 9, 3106.

[38] Y. Yan, A. P. R. Johnston, S. J. Dodds, M. M. J. Kamphuis, C. Ferguson, R. G. Parton, E. C. Nice, J. K. Heath, F. Caruso, ACS Nano 2010, 4, 2928. 


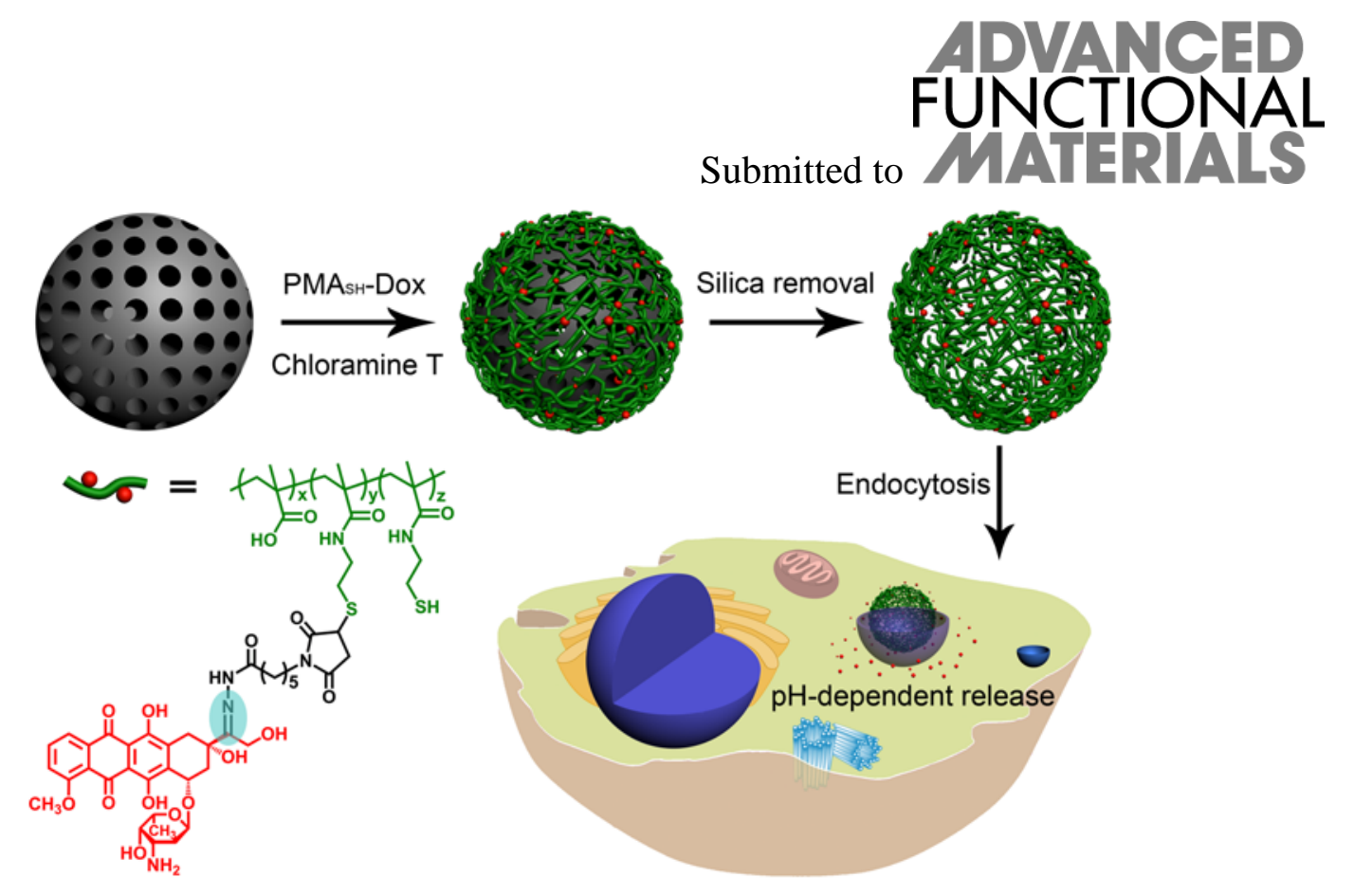

Scheme 1. Schematic illustration of the modular assembly of drug-loaded polymer particles and $\mathrm{pH}$-dependent drug release after endocytosis in a cancer cell. The structure of the polymer-drug conjugate is also shown. The labile hydrazone bond, which facilitates drug release, is shaded. 


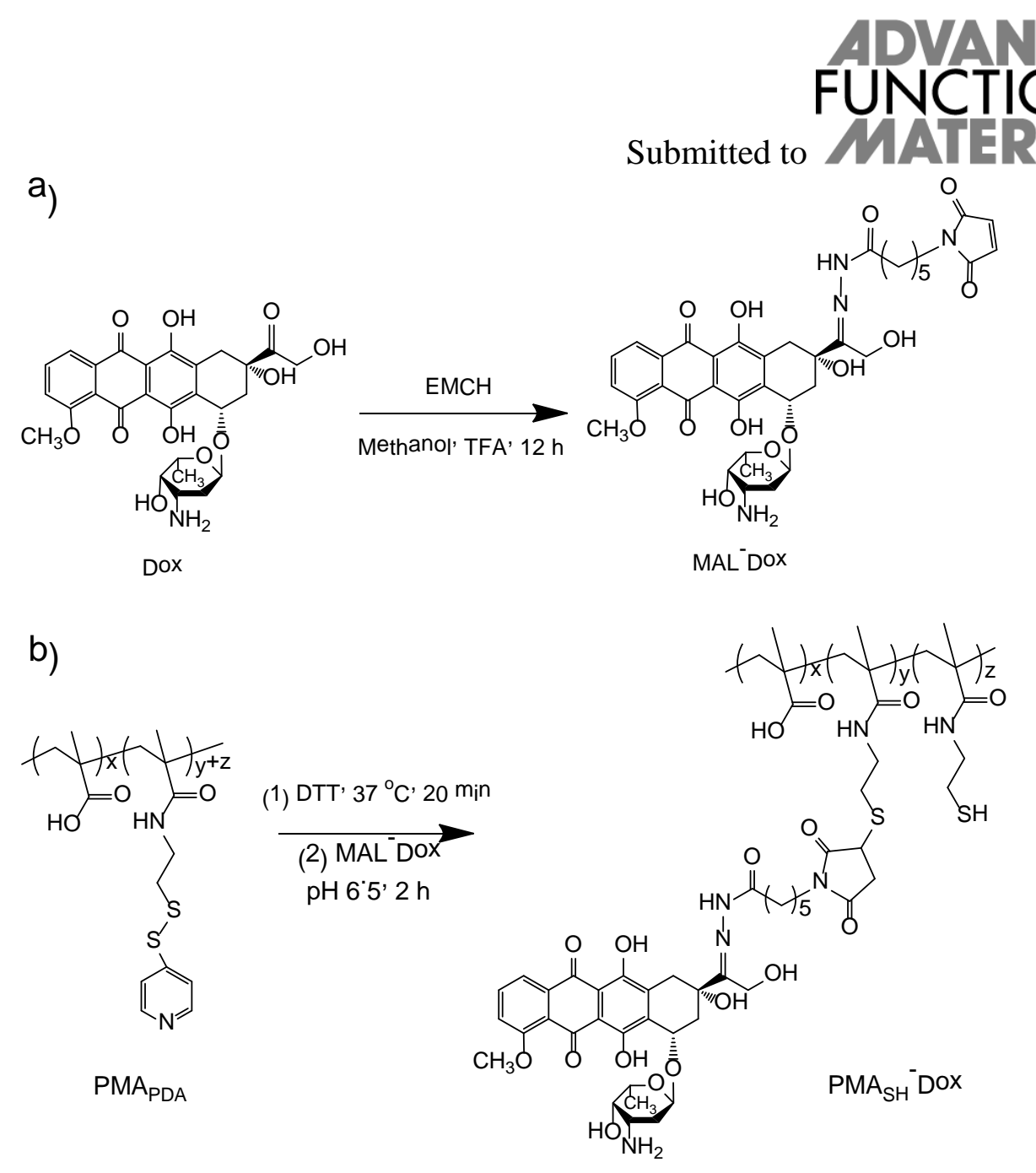

Scheme 2. Synthesis of a) MAL-Dox via hydrazone click chemistry and b) $\mathrm{PMA}_{\mathrm{SH}}$-Dox via thiol-maleimide click chemistry. 


\section{Submitted to}
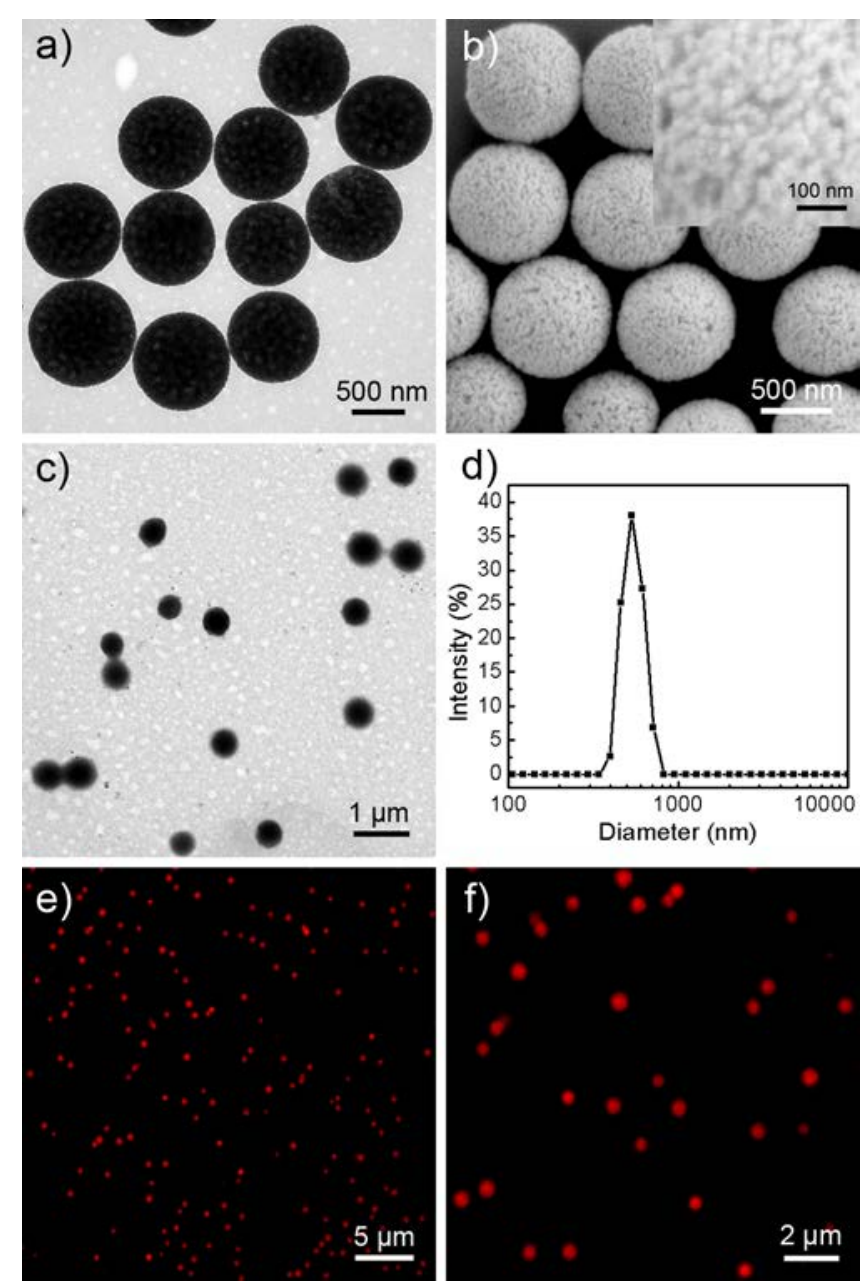

Figure 1. a) TEM and b) SEM images of MS particles. The inset in b) is a highermagnification image of the surface of a MS particle. c) TEM image, d) size distribution, and e,f) CLSM images of PMA $\mathrm{SH}_{-}$-Dox particles after removal of the MS spheres. 


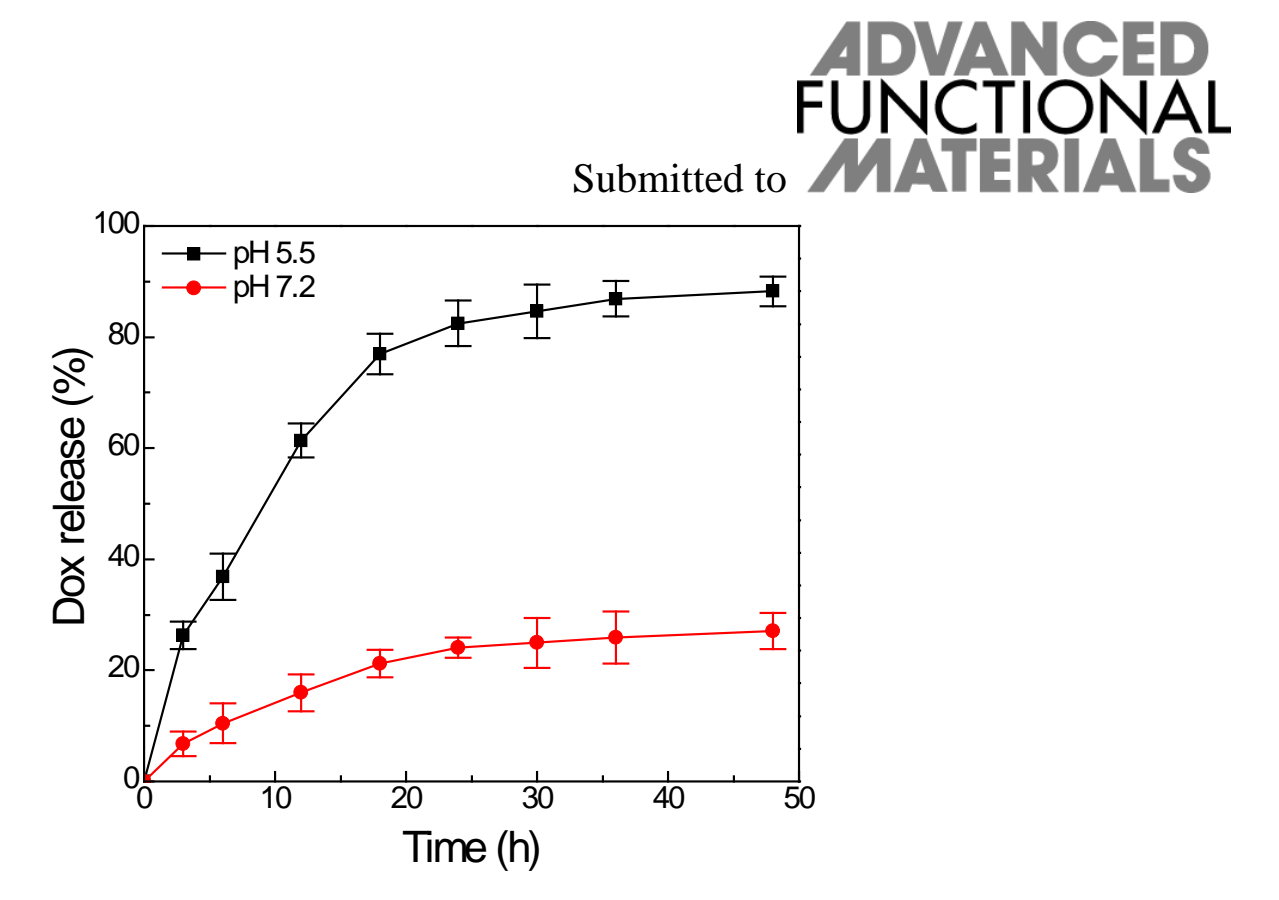

Figure 2. In vitro Dox release from $\mathrm{PMA}_{\mathrm{SH}}$-Dox particles in $\mathrm{pH} 7.2$ phosphate buffer and $\mathrm{pH}$ 5.5 acetate buffer, respectively. 


\section{Submitted to

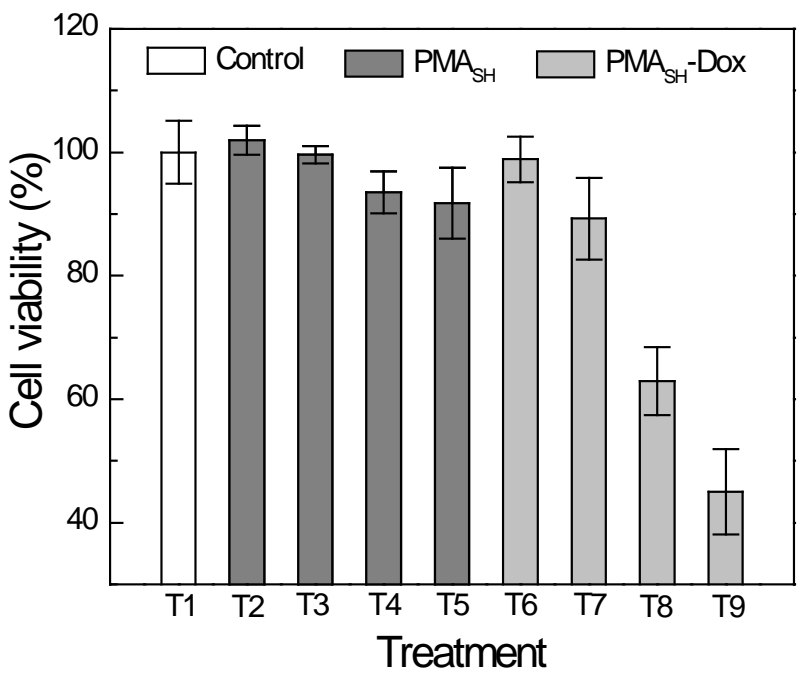

Figure 3. Cell viability of LIM1899 human colorectal cancer cells in the absence of any external agent (T1), in the presence of PMA $\mathrm{SH}_{\mathrm{SH}}$ particles (T2, T3, T4, T5) and PMA $\mathrm{SH}_{\mathrm{SH}}$-Dox particles (T6, T7, T8, T9) after $43 \mathrm{~h}$ incubation. The ratios (particles to cells) used for each treatment are 1 (T2, T6), 10 (T3, T7), 100 (T4, T8), and 1000 (T5, T9), respectively. The cell viability has been normalized by setting the viability of untreated cells as $100 \%$. The results shown represent the average of three independent experiments, each performed in triplicate. 

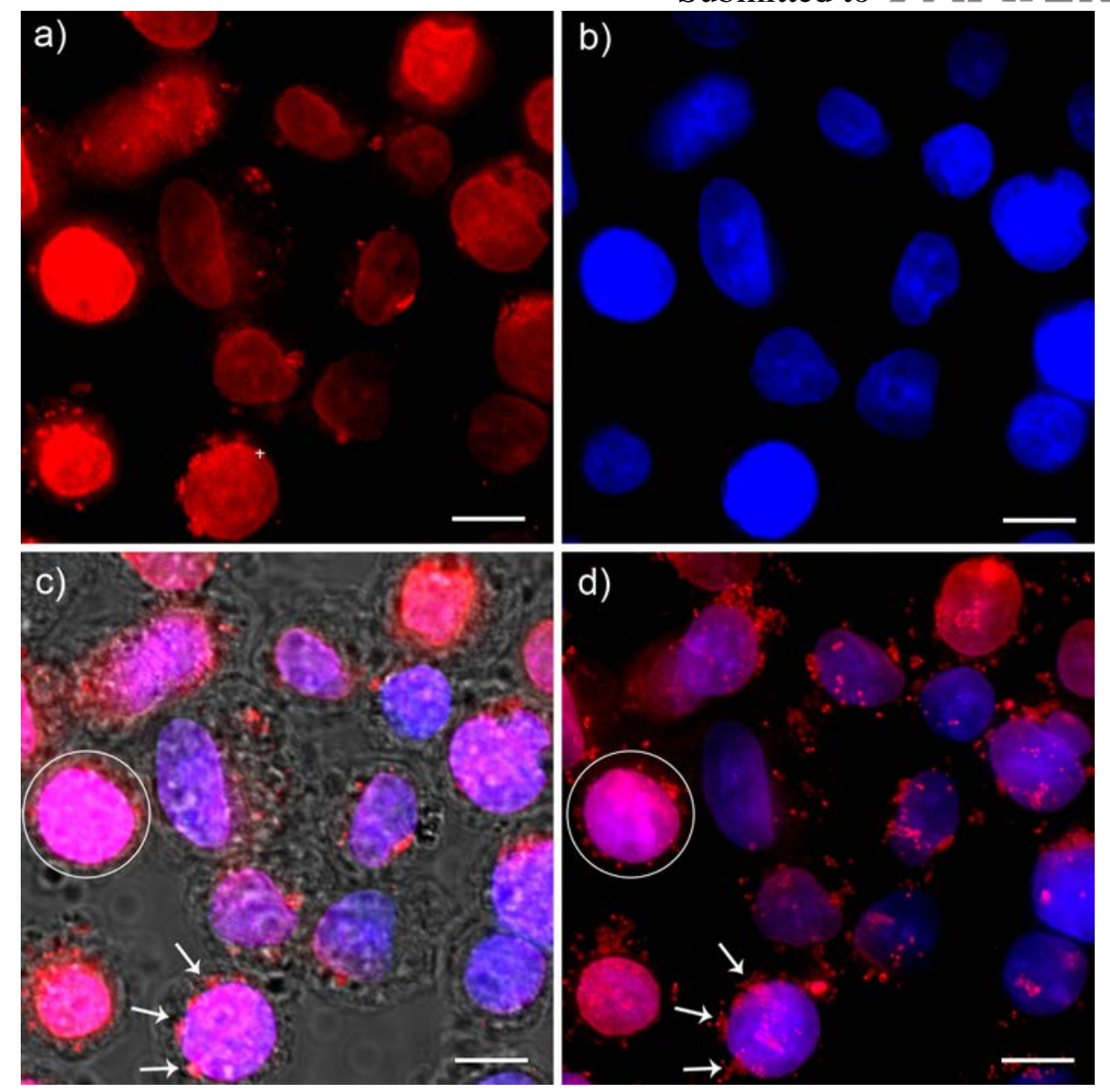

Figure 4. Representative deconvolution microscope images of LIM1899 cells treated with PMA $_{\mathrm{SH}^{-}}$Dox particles at a particle to cell ratio of 1000:1. a-c) Focal plane microscopy images. a) Red fluorescence corresponds to Dox; b) Nuclei were stained blue with Hoechst 33342; c) Merged image of Dox, Hoechst, and bright field, showing the localization of Dox in the nucleus; d) Blended 3D image showing the distribution of Dox in the entire cells. The circles and arrows in c) and d) highlight the Dox-associated fluorescence present in the cytoplasm and concentrated in vesicles at the perinuclear region. All scale bars are $10 \mu \mathrm{m}$. 


\section{Table of Contents}

\section{Templated Assembly of pH-Labile Polymer-Drug Particles for Intracellular Drug Delivery}

Jiwei Cui, Yan Yan, Yajun Wang, and Frank Caruso*

Keyword: Drug delivery

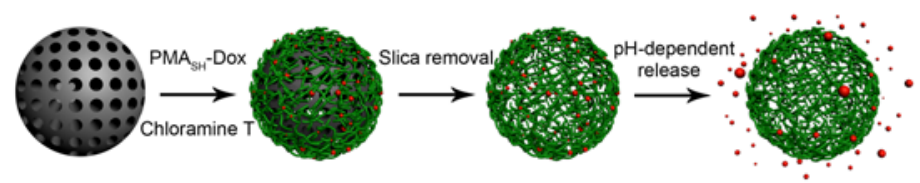

Polymer-drug particles, prepared using a facile mesoporous silica templating method, were stable at physiological conditions and allow the triggered release of the encapsulated drug at endosomal/lysosomal $\mathrm{pH}$. Cell viability assays showed the particles resulted in significant cancer cell death after internalization. The reported particles represent a novel and versatile class of stimuli-responsive carriers for controlled drug delivery. 


\section{University Library}

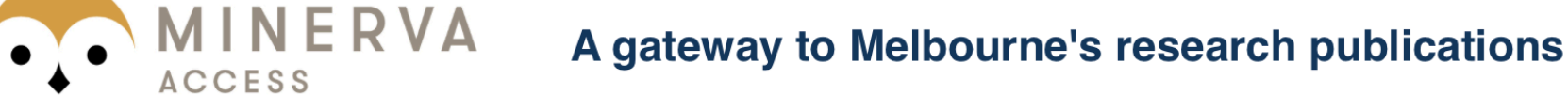

Minerva Access is the Institutional Repository of The University of Melbourne

Author/s:

Cui, J;Yan, Y;Wang, Y;Caruso, F

Title:

Templated Assembly of pH-Labile Polymer-Drug Particles for Intracellular Drug Delivery

Date:

2012-11-21

Citation:

Cui, J., Yan, Y., Wang, Y. \& Caruso, F. (2012). Templated Assembly of pH-Labile PolymerDrug Particles for Intracellular Drug Delivery. ADVANCED FUNCTIONAL MATERIALS, 22 (22), pp.4718-4723. https://doi.org/10.1002/adfm.201201191.

Persistent Link:

http://hdl.handle.net/11343/123314 